\title{
The Role of Social Capital in Shaping Management in Jordan: A Case Study on Umniah Company
}

\author{
Martin Harris \\ School of Business, Essex University, England \\ E-mail: martinh@essex.ac.uk
}

Naser Khdour

Business Administration Department, Philadelphia University, Jordan

E-mail: nkhdour@philadelphia.edu.jo

\begin{abstract}
Ahmad Al Maani
Business Administration Department, Philadelphia University, Jordan

E-mail: Amaani@philadelphia.edu.jo

Naser Saif

Hospital Management Department, Philadelphia University, Jordan

E-mail: nsaif@philadelphia.edu.jo
\end{abstract}

Received: Dec.13, 2014

Accepted: Dec. 21, 2014

Published: January 1, 2015

doi:10.5296/jmr.v7i1.6775

URL: http://dx.doi.org/10.5296/jmr.v7i1.6775

\begin{abstract}
This research describes a research project that examines the role of social capital in shaping management in the Jordanian telecoms sector, more precisely Umniah Company. In doing so it has sought to examine the relationship between social capital and the emergence of specifically 'Arab' approaches to management. Case study investigation is used to explore and elucidate the 'lived experience' of management in this organization. The interviews material has shown that social capital is playing a major role in shaping the practice of management. The case study provides empirical support for the idea that this is sustained by networking behavior, by relatively high levels of trust and by the existence of shared norms. The lack of
\end{abstract}




\section{Macrothink}

Journal of Management Research ISSN 1941-899X 2015, Vol. 7, No. 1

studies on social capital from a management perspective and the lack of studies of such research in the Middle East in general, more precisely Jordan, make this research a path finding research and contributes toward the development of Jordan and contributed towards Arab management by entering Arab management in the management discourse.

Keywords: Social Capital, Network, Trust, Norms, Management, Middle East, Jordan. 


\section{Introduction}

Social capital has evolved over several years (Putnam, 1995; Bankston and Zhou, 2002; Labonte, 1999; Lazega and Pattison, 2001). The term is associated with social connectedness and civil society (Adam and Roncevic, 2003). The concept has been developed by Bourdieu, Putnam and Coleman to express the social relationships between people that facilitate beneficial outcomes (Szreter, 2000). The term social capital refers to the individual's store of social trust and networks that people can use to resolve their daily problems. Lack of social capital has been seen as an explanation for social problems as varied as crime, poverty, economic inefficiency and inefficient government (Boix and Posner, 1998).

There has been a growth in the discussion of social capital in academic literature over the last ten years (Aldridge et al. 2002). The concept of social capital is suitable for a variety of applications since researchers can investigate any social situation through the conceptual structure of social capital (Grootaert and Van Bastelaer, 2002b). In proposing a fourth paradigm of management to describe the unique style that has emerged in the Arab world, Weir (2001) has suggested many opportunities for applying research on social capital. In order to situate this, there is a real need to explore the idea of social capital where the kind of relationship, ties, norms, beliefs, and trust between people, have been considered as the major aspects of this concept.

Some have argued that although social capital was originally conceived as a community notion, it should be visible at the individual level (Brewer, 2003). Others have disagreed with this assertion, noting visibility at both a community and an individual level. Given that Bourdieu and Wacquant (1992) recognized it at the individual level and that Putnam (1999) more recently at the community level. Others have argued more in favor of the social structure, that social capital is not a characteristic of individuals but a context dependent feature of the social structure (Hogan and Owen, 2000) Much research has posited that social capital is a feature of the community. Indeed, Newton has argued that social capital and civil society are fundamentally social and collective aspects of social systems, rather than a characteristic of individuals (Newton, 2001). The important difference between human and social capital is that social capital is found in relations between individuals and groups, and not in individuals (Edwards and Foley, 1998). The general agreement in the literature is that social capital is identifiable from the individual level to the level of the nation however it is clear that social capital is evident at any level where there is identification and belonging. Social capital can be categorized as having three essential levels the micro, individual level, the meso, group level and the macro, societal level.

\section{Study Problem}

The concept of social capital (Coleman, 1988; Nahapiat, 1998, Adler, 2002) refers to associational norms and sociability, however, how have these factors influenced the development of 'management' as a discrete social activity in Jordan?

\section{Research Aims and Objectives}

This study aims to explore the literature of social capital; to examine the relationships 
between these factors that contribute to the available literature. It also aims to provide useful conclusions and recommendations to illuminate the role of social capital in shaping the management of the telecoms sector in Jordan. Thus, this study also aims to examine management in the Arab World and discuss its relation to business.

\section{Question of the Research}

In order to achieve the goals and objectives of this research, this paper will try to answer this question: What specific forms of social capital have influenced the development of management as a discrete social activity in Jordan?

\section{Contribution of the research}

This paper has contributed new knowledge about social capital, and Arab management, since there is a scarcity of such research in Middle Eastern countries. According to Cohen and Prusak (2001) the idea of looking at social capital in firms and organizations is relatively new, thus, by making social capital the bedrock of this paper it has contributed unique knowledge about social capital to the research literature.

The research interest and application of the concept may perhaps suggest the theoretical importance of social capital theory. Existing studies, some researchers have provided abundant evidence of its occurrence and offered valuable examples of its political, economic and social influence (Jack and Jordan, 1999; Montgomery 2000). Even though social capital is a sociological concept, this research has taken the concept of social capital and applied it to a management content and management discourse and examined the influence of social capital on the management in Jordanian telecom organisations. Moreover, this research was carried out in Jordan with the aim of understanding the role of social capital in shaping management within the Jordanaian telecoms sector. Consequently, the main contribution of this research comes from the fact that this research is one of the first to be carried out in Jordan and in the Middle East.

The majority of social capital benefits described in the literature have not been empirically tested but arise from theoretical extrapolation from other concepts (Aldridge et al, 2002; Halpern, 2001). However, in this research social capital has been empirically tested with the use of an exploratory approach.

\section{Literature Review}

The concept of social capital has been increasingly prominent in recent accounts of the economy and society, particularly those that seek to show the role of trust and community in countering the anomic effects of market values on contemporary restructuring.

The term social capital appeared for the first time in 1916 (Cohen and Prusak, 2001: 4) The term was later taken up by writers such as, George Homans, John R. Seeley, and Jane Jacobs whose work on the decline and rise of American cities focused on the value created by social networks, for example those found in close knit neighborhoods. Social capital can be seen as a 'hidden' form of capital, Lin (2001) has argued that the best understanding of social capital can be gained by focusing on the mechanisms and processes in the resources of social 
networks which should be treated as an investment (Cohen and Prusak, 2001).

Coleman and Bourdieu, have given the concept some additional academic credentials. Bourdieu pointed out the importance of cultural capital on helping individual achievement and he acknowledges that social capital is to be considered as a form of Capital. Coleman's work on 'Social capital in the creation of human capital' and in 'foundation of social theory' has attempted to correct the individualist bias of human capital theory, and he believes that actual returns for the organization can be achieved under the notion that investment in people is not enough, but it is important to look at the position those people occupy or the network to which they belong (Cohen and Prusak, 2001).

Social capital has been defined in several different ways depending on the perspective of particular disciplines (Robison et al. 2002). Generally all definitions are in agreement that social capital has beneficial aspects for individual members of society and presumably society itself. The literature indicates that social capital does not have a definite definition on which all theorists agree. In the social capital discourse, despite the popularity of the concept, there is a challenge to agree upon an acceptable and useable definition, which reflects the risk of social capital being used as a metaphor. Understandably, different definitions of social capital will produce contradictions and disagreement on the notion of social capital (Adler and Kwon, 2002).

Robert Putnam described social capital as 'refers to features of social organizations such as networks, norms, and social trust that facilitate coordination and cooperation for mutual benefit' (Cohen and Prusak, 2001: 3). Cohen and Prusak (2001:4) defined social capital as 'social capital consists of the stock of active connections among people, the trust, mutual understanding, and shared values and behaviors that bind the members of human networks and communities and make cooperative action possible'.

Social capital is usually regarded as the link between social networks and the bonding of people, through reciprocal relationships (Dekker and Uslaner, 2001; Uslaner, 2001). Such relations are based on a mutual or cooperative interchange of favors or privileges. Sander has argued that the perception that 'more people get their jobs from whom they know, rather than what they know, turns out to be true' (2002: 213). Adler and Kwon (2002) have examined the research on social capital and have noted that the guiding principle of much research is the notion that social capital is a valuable resource for individuals. Indeed, they have defined social capital as 'the goodwill available to individuals or groups. Its source lies in the structure and content of the actor's social relations. Its effects flow from the information, influence, and solidarity it makes available to the actor' (Adler and Kwon, 2002: 23). Others have suggested that social capital is essentially about how people interact with each other (see Dekker and Uslaner, 2001).

Social capital theory can be explained in terms of the various components of the theory. However, as mentioned above, social capital has many dimensions and theorists and researchers from different disciplines tend to emphasize particular dimensions when defining social capital. It is important to note that each dimension of social capital is not able to fully capture the concept in its entirety (Hean et al., 2003). The main components of social capital 
are generally viewed as trust (see Putnam et al. 1993), rules and norms governing social action (Fukuyama, 2001), types of social interaction (Snijders, 1999), and network resources (Kilpatrick, 2000).

The idea of looking at social capital in firms and organizations is relatively new (Cohen and Prusak, 2001). However it can be argued that social capital has some characteristics of the other types of capital, for instance it is a resource one can build up and later you can draw on, so they start to change the status from social fabric to social capital in their understanding of the world from economic perspectives.

For any organisation there are common concepts about capital in daily use such as financial capital and the human capital. These are very important for the organisation's growth and to make sure that the organisation performs well, and that the people inside the organisation believe that by employing these two capital types the organisation will grow. But what about starting to think about Networks and relationship as an asset of this organisation?

People in their relationship in families, communities and other social networks have different kinds of resources; social capital is the best term to describe this kind of resource, something like bridge when trying to bond people together. Promoting a sense of shared identity through networks and by using their communications with others, and in helping people to make the linking to opportunities and structures of support to develop capacities.

Cohen and Prusak (2001) pointed out that the 'human need for membership and identification, the satisfaction gained from recognition by peers'. When it comes to measuring and finding one common definition for social capital it is a complex and difficult task, but the researchers can describe and define the social capital as social glue that keeps people together in the same content in families and communities. The uncertain environment the world lives in these days, gives the priority to social capital to work well by giving the sense of developing the belongingness in the relationship, while one is doing things for the other one and the normal outcome will be the trust between them.

Despite the fact that social capital is not the answer to all business matters or a predictor of organizational success, trust is a precondition of a really cooperative work. It lowers transaction costs and other organizational friction and provides a base for other social capital benefits, furthermore, Cohen and Prusak (2001:29) highlighted 'Trust as the essential fuel of social capital engine". They argued that trust is the one vital lubricant to all social activities, allowing people to work and live together without generating conflict and negotiations. In addition, John L. Locke in Cohen and Prusak (2001) stated that " Trust is like the air we breathe it is basic to all human activities. A feeling of trust enables individuals to do things on their own ".

Cohen and Prusak (2001) argued that trust or distrust issues have become pervaded, trust habitually grows from personal contact in the fullness of time, people sometime start to trust or distrust each other when they meet, maybe by using intuitive judgments such as to how people look, and sound, the way they shake hands, the talent to engage in small talk, and how they react to different people (2001: 31). Francis Fukuyama labels intuitive trust as 
"Spontaneous sociability" However, others argue that the trust or distrust comes from the quality of reputation of someone's workplace. This also has an influential outcome and sometimes people presume that members of certain professions are expected to be more trustworthy than member of other professions.

The situation is the same when the case is about trust in organizations. Cohen and Prusak (2001) pointed out that to a great extent the trust subsists in organization is the identical kind of trust that exists between individuals, connected pair by pair through " quick trust " and judgments derived from reputation and experience. Mutually first impression and assessments which is done through experience and observation work within and outside organization in the same manner.

\section{Research Methodology}

A qualitative approach for this paper has been adopted in order to meet the stated aims and objectives and answer any questions that arise. This was due to the exploratory, interpretive and inductive nature of such an approach. The study examined Jordan's telecommunications sector, more precisely Umniah Company. The data was collected by the use of thirty semi-structured interviews. The qualitative programme NVivo was employed for analysis and by organising the data's themes facilitated its analysis.

\subsection{Data Collection}

A combination of fieldwork and a relevant literature review was conducted for a thorough examination of social capital and factors that affected the build up of social capital in the area of Jordanian telecoms. A qualitative approach is followed throughout this research. The main data collection method was from semi-structured interviews. The semi structured interviews selected are in accord with the nature of qualitative research and involve the various perspectives of 'lived experiences' of the participants' understanding of social capital in Jordan's telecommunications (Bryman and Bell, 2003).

In total thirty interviews were carried out in Umniah Company. The interviews were designed to include the three levels of managers, supervisors and employees. The interviews covered the two main departments in the company which are the human resources department and the marketing department. In each department, fifteen interviews were carried out to include three managers, three supervisors and nine employees.

Good relations with the employees of Umniah Company were established by the researchers, by the use of this method of data collection. The researchers spent three months observing occurrences of social capital in this sector, which permitted the opportunity of not only learning about social capital but also having the chance to 'feel it' (Gill and Johnson, 1997).

\section{Findings}

\subsection{The existence of Networks}

The interviewee's statements revealed that a Network is considered as the basic way of running the business at Umniah. Many different situations emerged that do demonstrate the 
way the Network works. The Network takes place in the daily life of the employee's organizational activities, while employees are interacting and contacting other people in other departments. Basically these departments are interlinked; they are not separated from each other even though they are undertaking different tasks. However, there is a requirement to contact each other because of the nature of the tasks and the duties of each department. This was reported in the following:

I would like to keep my good relations with the finance with the budget, and planning people because the overall daily work tasks are so related. So we need to contact with them (C1, E1.M)

In the telecoms sector a strong consideration has been given to both personal relationships and an informal way of undertaking the business. As such, this has created another significant indicator of the strong existence of, and a huge dependency on a Network; as a result employees are expecting a constant and fast running of business and swift achievements of their tasks. However, the mutual benefit is taken into consideration between the employees where everything has a return, so when help is given to somebody today this usually entails doing a favour for another later. Thus, in Umniah employees do believe in the saying that "as much as you know people, as much you get the things that you want". This is evident in the following:

Definitely (the Network) works 90\% the way we are running the business we depend on the Network. Not because of "Wasta" but because of personal relations, and if I called someone and I have better relations with this person my business will turn faster (C1,E4.HR)

The Network has been seen as a tool to help both managers and employees to run the business in a good environment. A Network breaks any barriers between managers and employees because of the friendly relationship. Indeed, it was revealed by a worker that:

We share our personal information out of the work time, we sit together a lot, and we go outside to the cinemas, so when they talk to me they do not talk to me as a manager (C1, S3.H.R)

\subsubsection{The importance of a Network in an organization}

This section explores the role the business Network plays inside an organization. As long as Networking depends on the connection between employees one part of this connection is the discussion that happens between them either in a formal or an informal way. Business or social discussion helps the employee to think out of the box because it is thought out with other divisions by using its communication channel. In any company there are people influencing the company, who are decision makers and they might design or make the strategy of the company, so they are the source of information. Networking is the chance to be updated and to obtain one of the following benefits. A break in the routine, escape from a hectic life, Information sharing, new information channel, Improvement in performance, increased work productivity and Knowledge sharing. 


\subsubsection{The creation of a Network}

This section explains the ways in which the Network has been built up and created in Umniah. These represent the employee's personal experience in the company and come from the daily life in the organization where social capital occurs. Network has been created through one of the following,

\subsubsection{Social circles}

Sure this Social circle is affecting the environment and the people who you socialize with, however, this applies to work and finally it will affect both Network and Trust. (C1, E3.M)

\subsubsection{Personal initiatives}

I tried to know the people and talk to them and to get their experiences but for the most departments I was working with members, I get to know them in person. It is my personal effort to do the contacts (C1, E3.M)

\subsubsection{Social charisma}

I believe that Networking depends on the character of the employee himself. Personally speaking I am one of those people who enjoy socializing, building team spirit maybe because I worked before in a call centre. I was a team leader so I know how to deal with people, how to treat them, not to mix the personal with business things but at the same time not to be solid at work, and to live in a friendly atmosphere but at the same time get things professionally (C1, E4.M)

\subsubsection{Age}

There was a good part; the majority of workers were young and it was so easy to deal with young people, and the environment itself was very comfortable where the employees are very friendly even my manager was young so it was easy to find common topics to talk about. (C1, E4.M)

\subsubsection{Lunch break and gathering}

Not all of my Networks were through meetings and business work; it could be through gatherings, the breaks, lunch time, and eftar at Ramadan where we gather and find things in common; then we start our Network from this step (C1, S3.H.R)

\subsubsection{The role of the company in building a Network}

All the events are sponsored by the company, we have a marketing outing each year, and the division manager conducts several team building meetings and lunch outings and dinners, and we go out for a football match (C1, E1.M)

\subsection{Trust in organization}

The discussion continuous to address the research question; which specific forms of social capital have influenced the development of 'management' as a discrete social activity in Jordan? 
The focus here is on the second element of social capital which was found to be Trust. Social capital mainly depends on Trust which is considered as a lubricant that facilitates the work environment in any organization to be healthy, and it aids the move toward achieving the organization's mission and vision.

\subsubsection{Trust in Umniah}

By asking different employees, the researchers obtained a clear impression that employees Trust each other; moreover, they do believe in the concept of Trust, and their comments about Trust is part of the social structure between people in the organization. They never expected researchers to ask them about Trust since Trust is something they have a sense of; neither were they expecting somebody to measure its existence at Umniah, as an Organization. However, Trust is something they build up in their daily life between each other, over time, or by first impressions:

I am sure that my division is full of Trust and is a friendly one. In my case, I Trust the majority of the people I work with and generally the atmosphere is very relaxed (C1, E2.H.R)

\subsubsection{Definitions of Trust}

Trust seems to be defined in different ways by managers and employees, such definitions depend on different point of views as a result of their different understanding of Trust and according to their daily life and experience.

\subsubsection{Trust: Being open with the employees}

At the managerial level, Trust has been portrayed in two ways; the first has focused on being open with colleagues so they could talk freely without any barriers between them. However, this form of Trust can be considered as a reflection of the employees themselves, since such Trust will affect the way the employees predict their manager, predict their reactions and The discussion continuous to address the first research question; which specific forms of social capital have influenced the development of 'management' as a discrete social activity in Jordan?

8.2.2.2 Trust: Dependency on others with full information sharing in a confidential environment

Trust is a feeling of safety in the organization, and is a dependency on other employees to help me to do the business with full sharing of information without any restrictions; Trust is to have somebody to support me, to have someone pushing me and work as a back up and I know that they (management) are fighting for us, and this will give me Trust (C1, S5.M)

\subsubsection{Trust: good faith in work}

For me Trust is that I know that they do not want to hurt me, and they won't do anything to hurt me. Also in terms of professionalism, they won't do things on purpose to make my project fail or they won't send me wrong things on purpose, and then of course something like not gossiping and talking behind my back. Because gossiping is something that goes against Trust as long as we Trust each other there is no need to gossip. $\quad$ (C1, E2.H.R) 


\subsubsection{Building Trust in organization}

The following discussion is presented in-depth to enable a deep understanding of what issues affect the building of Trust inside Umniah. A reflection of the employee's awareness of the concept and which factors and issues play a key role in building Trust are discussed.

\subsubsection{Commitment toward the work}

The people who work hard and totally do the job properly, increases our Trust as a management toward them because they do the tasks in a brilliant way and they are always committed and feel that they are talented.

(C1, M1.H.R)

\subsubsection{Personal Experience}

I depend on my feelings and experience, sometimes I have the feeling from the first look, and the first impression that he or she is a Trustworthy; many times I got this impression. And some of them are open to you where they give you Trust while I am working with them. We Trust some by nature that you like this person or not, you feel directly that he is really good. (C1, E5.H.R)

\subsubsection{Time}

Working together for almost 6 years, 8 to 9 hours per day five days a week; so we are spending more time here than what we do at home and that is enough to build Trust ( C1, E5.H.R)

\subsubsection{Personal trait and culture affects}

It depends on the Trust to know whether others play fairly or not. But you cannot Trust anyone; it depends on the behaviour and the character of the people. Maybe if I Trust people then maybe I will Trust all my colleagues, but even if I do not Trust my husband or my mother then I will never Trust anyone; I think it is a personal issue and skill. (C1, E1.M)

\subsubsection{Work environment}

We are the youngest, I mean the employees are younger than the others in other companies and competitors so the nature of the environment we have is different; I feel free to leave the work for these two and they can make it even better than I mentioned because I Trust them. But we do not have this, we do not gossip. We do not have such environment in Umniah; honestly, we do not have gossiping environment. We are a small cooperative team (C1, M1.H.R)

\subsection{Norms in Organizations}

To complete the previous argument and answer the research question; which specific forms of social capital have influenced the development of 'management' as a discrete social activity in Jordan? The following section explores the effect of Norms in Organizations. In this section the discussion addresses how the employee in the Umniah Company understands Norms; in addition, the current status of Norms in the organization is also investigated. 


\subsubsection{Employees understanding of Norms}

Norms in an organization was found to be the third element of social capital. Employees understand Norms as having different elements. Employees understand Norms as something to do with sharing the same religion, language and ideas. It is surprising that the employees did not pay much attention to such Norms in Umniah.

\subsubsection{Current status of Norms in Umniah}

It seems that in Umniah Norms do not play a role in the organization. The company is a combination of non Muslim and non Arabs nationalities, many overseas, university students work there; that is to say, many managers have graduated from Western countries and have gone on to lead the company. The three general notions of Norms, linked to religion, language and ideas have been replaced with the company policies, and these apply to all employees:

The Norms in [the Umniah] telecoms [company] are the companies policies' I don't think it has anything to do with sharing the same religion, same language, and same ideas. Thus, these Norms push the employees to have a high level of Trust and a high level of Network because we have so many non Muslims and non Arabs here in the company and there are many staff from Oxford University. (Asks the researcher 'Do you know them, they are working here). Most of the managers are Foreigners and not Muslims or Arabs. Company policy comes first; so again the Norms are the company policies, not related to religion, customs or Islam (C1, E4.H.R)

\subsubsection{Advantages of Social Capital in Umniah}

While this research looks at the role of social capital in shaping management as a discrete social activity in Umniah Company in Jordan, Networks and Trust has been found to be two elements of social capital. Both elements generate many advantages to both employees and management. However, to present a clearer picture of Arab management, the following section explores the main advantages of social capital in organizations. However, to present a clearer picture of Arab management, the following section explores the main advantages of social capital in organizations. Minimize business risk, Reduce transaction cost, Belongingness and loyalty toward the organization, Reputation inside and outside the company, Good work environment, increased knowledge sharing, Low employee turnover, Minimize conflict within the organization, Making the work easier and more efficient, Spirit of cooperation.

That [having an extensive Network and Trust in Umniah] helps us in being efficient; so if we are a bureaucratic company, we will not be achieving what we are doing now. We have fewer employees and we have more competitive budgets; so it is really hard for us to survive if we do not have such a good Trust environment (C1, M1.H.R)

\subsubsection{Disadvantages of Social Capital in Umniah}

Like anything else in life which can have advantages and disadvantages, social capital has some disadvantages. The company should be familiar with these downsides and endeavour to 
control them. The section below points out the main downsides which have been discovered about Umniah in the research data and these were found to be related to gossiping, the possibility of gangs and the waste of business time.

\subsubsection{Social Capital and the existence of gossiping}

Gossiping in a business may create major problems in a work environment and for employees. Gossiping may affect employees directly through being misjudged, and such action may lead to employees receiving warning letters from the HR department, or being called to see the director and questioned about such actions. All employees would preferably like to avoid such repercussions at Umniah.

The most common place for gossip is in the company kitchen and water station. The main reasons for gossiping in Umniah are related to two main reasons; the first one is the long working hours. In fact the employees work from eight in the morning to five in the afternoon. The second reason is that employees are social by nature. The extensive Network system in Umniah makes gossip something that could not ignored:

It [gossip] is part of the daily tasks; then gossiping is here. You know two years Ago in Umniah no one in Umniah approached me with any gossip because I am Not an open person, but when I made some friendships, they started to gossip to met. When I go to the "cafeteria to eat a sandwich, I do hear some gossiping' so there is Gossip and they increase wherever there is Network. (C1, E1.M)

\subsubsection{Social capital creates gangs}

Another disadvantage of having high level of social capital in Umniah is the probability of having gangs amongst the employees. The bad effect of gangs occurs when people get to know each other to maximize their own benefit, however, that will affect the reputation of the company and provide a misleading picture of the company. Gangs have been portrayed as a small lobby or a small group inside the big group. Gangs could be between departments or between people, however gangs are looked at as a reflection of the clannishness's inside the organization where the formulation of these gangs depends on the region where the employees come, from which is the same logic of the clans system in Jordan.

There are many people who are working for themselves not for the company's target. By the way, you can think of that as a disadvantage of the small group inside the big group because when they start to have more power and authority they will work against the company's mission and vision and will try to maximize their profit not the company's. They will be a small group inside the big group. (C1, S5, M)

\subsubsection{Wasting of business time and unneeded relations}

Employees believe that the Network is built on personal relations between each other. Therefore, this entails taking some of the business time to create such relations; in addition having high Trust environment and an extensive Network between employees could delay the work and keep it postponed. Moreover, knowing more people outside your Network cycle may not be useful for efficiency in the workplace: 
Sometimes it is a waste of business time because they are using part of this time for the personal issues and because of the good relationships.

$(C 1, S 5, M)$

\section{Discussion}

\subsection{Networks in Umniah}

Preliminary analysis of the case study findings suggested that networking within this organization was of prime concern to interview respondents. The emphasis placed on networking originated from a deep belief in the importance of the people within organization and the surrounding business environment.

Major common benefits associated with networking included knowledge sharing, improvements in an organization's performance, delivering work quickly and efficiently, problem solving and information sharing. The participants working at Umniah reported different benefits, associating network behaviour with breaks in the routine, escaping from a hectic life and pressure to increase work productivity.

Umniah has agreed on the following factors that create a Network. The fieldwork revealed a common concern with personal initiative, social charisma, age and opportunties for the formation of networks. The participants in the Umniah Company, for example, noted social circles, the lunch break gatherings, working in a previous company and the department.

\subsection{Trust in Umniah}

The fieldwork and data gathering suggest that high levels of trust exist within Umniah. When talking about Trust with the participants the researchers had the impression that Trust was an important concept for them even if they found this difficult to separate from other aspects of daily organizational life. Trust was seen a part of the 'lived experience' of daily life within the organization. A close examination of the interview material produced a series of different definitions and constructions of trust by different employees.

Trust in the Umniah Company was construed as being open with the employees; the dependency on others with full information sharing in a confidential environment and good faith in work.

Two issues raised by the interviews at Umniah are the work environment and the predictability of the managers behaviour. The predictability of manager behaviour has been discussed in Cohen and Prusak (2001). They noted that the leaders set up and sustained the organizations' values and Norms during their actions which will affect the general political environment and cultural 'tone' of organizational life. On the one hand, when those leaders behave in certain ways, such as being fair, reasonable, and reliable it will affect the way employees feel towards these behaviours, and such traits will spread through the organization that will help for more trustful environments. On the other hand, when those leaders start to behave in variable ways, such as being biased, or dishonest the organization will reflect these qualities as well.

One important source of organizational Trust as pointed out in Cohen and Prusak (2001), is 
the role played by 'Ttrust brokers'. This role helps to spread trust throughout an organization. For example, if you need someone to do a vital and complicated piece of work, you will most likely trust a person that has been recommended by a highly trusted colleague who knows you and your requirements. But if that candidate is too busy to do that work, a recommendation given by another person will take place, and they might say 'I know somebody who would do it well'. This occurs because trust in that person has already been established, and if that person is also busy, another suggestion will be made, and this will continue and the acceptance and generalization of trust will extend from person to person, until a person can be found to undertake the piece of work. In addition, an individual's reputation plays an essential role in assessing particular forms of trustworthiness, particularly in the absence of personal experience.

\subsection{Norms in Umniah}

This section will discuss the relationship between social capital and the question of shared norms within Umniah organization. Norms have been linked and understood as sharing Islam as a religion and Arabic as a language, sharing the same ideas and background which have been shaped by the Jordanian culture, and the traditions, habits and folklore within this culture. Whilst the two preceding research themes (networking and trust) appear as core features of organizational life, it would appear that Arab cultural norms have been supplanted by company policies, formal procedures, and guidelines as seen for example in formalized company code of ethics. According to Weir's (2001) analysis of management in the Arab world, he argues that it is impossible to overlook the central role of Islam as this, "provides a matrix of belief that is manifested in behavioural practice...' (2001: 17) a nexus of connecting values, and a 'common culture', between members (Weir, 2001: 3) Whereas the western paradigm must pay to achieve a stable culture within the organization, Arab management practices already provided this foundation through Islam.

The case study findings suggest that 'management' is informed by three manifestations of social capital, network forms of association, trust and shared norms. The findings highlight several manifestations of social capital in Jordanian business and society. First, Networking allows employees to connect to different departments and functions within the organization.

Jordan has been described as a tribal society based on fealty and tradition rather than Trust. Whilst the connections between tribal members bring important mutual benefits. Jordanian society has also been described as a society based on collectivism. Collectivism is widely seen as being entirely opposed to individualism, thus, people tend not to so much think about themselves as about their group and their Network, thus, they tend to bring their own people around them in organization, applying the Jordanian saying "the face you know is better than the one you don't know". Also, a glance at the Arab culture suggests they do believe in knowing people and that is obvious from their habit of inviting others to join them in activities, even after they have only met them once, in order to Network with them and this creates more connections. Such connections are important for them if they want help and want somebody to support them on particular occasions. Thus, the culture is playing another role in building and giving priority to Networks, and later to trust, since some of the 
Jordanian proverbs, for example, "Don't Trust people easily" advise that individuals use the available Network for help initially, and then over time, and according to this dominant culture the trust will work as a second element, in the support system.

Thirdly, the gap in the Jordanian educational system, where there is no balance between the theory and the market requirements and practices, has pushed employees to depend more on their Network to prove to that they are good workers in the work place. This is evident when the research participants reported that workers tend to say 'it is not what you know, it is who you know'. Additionally, employees view the Network as a communication tool that allows them to run the business and deal with people, and then to trust them later. When employees need to trust somebody, they speak and communicate with the person first, so they need to Network first, then trust tends to follow.

Fourthly, by looking at the way Arab people tend to run their business, it appears that it depends on personal relationships using an informal network system, with the organization's rules and procedures allowing the Network to have the space to flourish, since it helps run the business.

Trust has emerged as a second element of social capital because it is linked to the goals of the business. Trust works as an aid to deliver the right work so there is no initial need to have trust on a personal level. This means if both employees share the same aim to deliver the necessary work to the company then it does not matter if they trust each other straightaway but trust is still very important in making the Network more powerful over time. Indeed, trust is about the sharing of information and confidentiality, and these things will make the Network more effective.

Norms has emerged as the third element of social capital because the Jordanian telecoms sector deals with an international companies and employees. However, in such a working environment diversity has to be respected since globalization has made the world a smaller place. Whereas, Norms has been understood as a sharing of the same language or religion, Norms is considered as a third element because the religion and the language are no longer derived from Jordan. The telecom organizations are dealing with a lot of people from overseas, both inside and outside their organization, such as Arab and non Arab, Christian and Muslim. They work with them and they are trying to learn from them. People from overseas are merged within the organization as a homogeneous mixture. Norms do not play a direct role in the development of the Jordanian management but it is important to mention that Norms are in existence but they are not applied in the organization, because the Jordanian telecom organizations do not have an Islamic management based on the Norms of the country, that is the Islam religion and the Arabic language. Instead the Norms has been replaced with the company procedures and rules, such as a code of ethics, and these have the control over management issues. Thus, Norms have been linked to respect, as a result of the organizational law and regulations, and employees are requested to respect each other and behave in certain ways, but on the other hand, there is nothing stated in the organization regulations that encourages the employees to trust people. 


\subsection{Advantages of social capital}

The discussion will now turn to the advantages of social capital in Umniah. There is an agrement that the main advantages of social capital is that it can generate within their organization, less bureaucracy, increased sense of belonging and loyalty toward the organization, low employee turnover providing social capital has been used as a retention tool, and finally social capital tends to provide a good work environment.

Some of these advantages have been discussed by Cohen and Prusak (2001). They pointed out that social capital provides certain benefits to organizations, such as improving knowledge sharing and maintaining organizational knowledge because of trust, common frames and common goals. In addition, social capital reduces the transaction costs because of a supportive spirit between the organization, the owner and the customer. According to (World Bank, 2011) social capital is used to reduce the transaction cost so any savings in time or in the information can be successfully dedicated to other tasks, such as, producing and marketing and the giving of more care to other products at a higher volume. Moreover, Social capital tends to reduce the transaction costs by limiting the need for explicit, detailed contracts and constant monitoring, When two parties understand and trust one another, they don't have to spend a lot of time, energy, and money on such things because they have a good mutual understanding of the task to be accomplished and they are confident that the other party will do the work well without needing constant supervision. According to the World Bank (2011), social capital plays an essential role in assisting collaboration and harmonization in organizations which minimizes transaction costs, and minimize the unnecessary bureaucracy, inadequate information, and negotiation.

\subsection{Disadvantages of social capital}

The following discussion will now focus on the disadvantages of social capital in Umniah. Interestingly, the Network was reported to be linked to the disadvantages. Each company regarded the existence of gossip and small groups in the form of lobbies and gangs. Cohen and Prusak (2001) argued that trustworthiness openness and transparency tended to minimize the disadvantages of social capital. Openness knowing what kind of people are within the organization, and what they are doing will help create connections and trust. Openness and trust work in combination to reduce the risk of any detrimental features of social capital, such as the production of small gangs of people. The authors argued that leaders ought to focus on a openness principle to permit each individual to enter and have access to the knowledge needed within the company. Additionally, permitting the employees to interact with people who have the required knowledge in the organization (2001: 46).

In addition to these two main disadvantages, the interviews carried out at the Umniah Company suggested another disadvantage that the accumulation of social capital may be associated with, 'wasted business time' and 'unnecessary relationships'.

Umniah Company had related issues attached to gossip, such as the sources of the gossip. The participants employed in the Umniah Company stated that the source of any gossip is hidden but employees gossip about things related to work, such as the hiring and firing of 
employees.

When it comes to evaluating gossip as a good or bad thing in business, Umniah Company has agreed that gossip have negative and positive effects but the perceived negative effects are more evident than the positive ones. The negative effects cited by Umniah respondents were associated with 'unrest' in the work environment and conflict between employees. This will affect the company's reputation and create a misbalanced relationship between employees and their management. On the other hand, Umniah employees pointed out that gossip could be regarded as positive when it encourages employees to behave in a respectful way with other members of the organization. Employees are aware that if they were involved in an incident, all employees would know about it the next day and will start talking and gossiping about it.

This research can be considered as ground breaking in the way it aimed to discuss social capital. This research is one of the first to rank the components of social capital. This is a new way to understand social capital; moreover, this research has worked in-depth to understand the influence of each one of the elements of social capital on management.

\section{Conclusion}

This research presented in this paper has investigated the role of social capital in shaping management in the Jordanian telecoms sector, more precisely Umniah Company. In doing so it has sought to examine the relationship between social capital and the emergence of specifically 'Arab' approaches to management.

The discussion presented in the previous section has argued that social capital is playing a major role in shaping the practice of management in Umniah Company. The case study provides empirical support for the idea that this is sustained by networking behavior, by relatively high levels of trust and by the existence of shared norms.

There is an agreement on placing the Network as a first specific form of social capital which has affected the development of their management activities as a discrete social activity in Jordan.

Trust has emerged as a second element of social capital .Whilst precise definitions and constructions of trust vary, knowledge sharing, transparency and reciprocity are generalized features of organizational life in this sector.

The existence of shared norms represents a substrate within Jordanian society but Umniah studied appear to have augmented this with highly western forms of substantive and formal rationality and this has fostered a much more inclusive approach in which Arab and non-Arab, Christian and Muslim personnel can mix. Traditionally Arab norms have been supplanted by company procedures, and rules.

Umniah has agreed and shared the main advantages that social capital has generated in their organization, which were a reduced level of bureaucracy, increased sense of belonging and loyalty towards the organization, low employee turnover as long as social capital has been used as a retention tool and, finally a good work environment. 
Umniah has agreed and shared the main disadvantages that social capital has generated in their organization. These were the existence of gossip and the creation of small groups, in form of lobbies and gangs. Also, social capital was seen as a waste of business time and unnecessary for the organization, and there was a detrimental effect on fairness and equal opportunities in the organization where favouritism and "Wasta " was a prominent aspect of the Arab culture.

The lack of studies on social capital from a management perspective and the lack of studies of such research in the Middle East in general, more precisely Jordan, make this research a path finding research and contributes toward the development of Jordan.

This research can be considered as ground breaking in the way it aimed to discuss social capital. This research is one of the first to rank the components of social capital. This is a new way to understand social capital; moreover, this research has worked in-depth to understand the influence of each one of the elements of social capital on management.

The significance of trust as an element of social capital is regularly alluded to in social science research but rarely examined empirically. The research presented in this paper sought to contribute to the existing corpus of work on ions of trust provided by the participants on the basis of their lived experience in their particular organizations.

\section{References}

Adam, Frane, \& Roncevic, Borut. (2003). Social Capital, Recent Debates and Research Trends. Social Science Information, 42, 155-183. http,//dx.doi.org/10.1177/0539018403042002001

Adler, Paul S, \& Seok-Woo Kwon. (2002). Social Capital, Prospects For a New Concept. Academy of Management. The Academy of Management Review, 27, 17-40.

Aldridge, Stephen. Halpern, David, \& Fitzpatrick, Sarah. (2002). Social Capital, A Discussion Paper. London, England, Performance and Innovation Unit.

Bankston, Carl L, \& Zhou, Min. (2002). Social Capital as a Process, The Meanings and Problems of a Theoretical Metaphor. Sociological Inquiry, 72, 285-317. http,//dx.doi.org/10.1111/1475-682X.00017

Boix, Carles, \& Posner, Daniel. N. (1998). Social Capital, Explaining its Origins and Effects on Government Performance. British Journal of Political Science, 28, 686-94. http,//dx.doi.org/10.1017/S0007123498000313

Bourdieu, P., \& Wacquant, L. P. D. (1992). An Invitation to Reflexive sociology. Chicago, University of Chicago Press.

Brewer, Gene. A. (2003). Building Social Capital, Civic Attitudes and Behavior of Public Servants. Journal of Public Administration Research and Theory, 13, 5-26. http,//dx.doi.org/10.1093/jopart/mug011

Bryman, A., \& Bell, E. (2003). Business research methods. New York, Oxford University 
Press.

Coleman, J. (1988). Social Capital in the Creation of Human Capital. The American Journal of Sociology, 4, Supplement, Organizations and Institutions, Sociological and Economic Approaches to the Analysis of Social Structure. The University of Chicago Press, S965S120.

Cohen, D., \& Prusak, L. (2001). In good company how social capital makes organizations work, Harvard Business School Press Boston, Massachusetts.

Dekker, Paul, \& Uslaner. Eric. M. (2001). Introduction. Pp. 1 - 8 in Social Capital and Participation in Everyday Life, edited by Eric M. Uslaner. London, Routledge.

Edwards, Bob, \& Foley. Michael, (1998). Civil society and social capital beyond Putnam. $\begin{array}{llll}\text { American } \quad \text { Behavioural Scientist, } & \text { 42, }\end{array}$ http,//dx.doi.org/10.1177/0002764298042001010

Fukuyama, Francis. (2001). Social capital, civil society and development. Third World Quarterly, 22, 7-20. http,//dx.doi.org/10.1080/713701144

Gill, J., \& Johnston, P. (1997). Research methods for managers. 2nd ed. London, Paul Chapman.

Grootaert, Christiaan, Thierry Van Bastelaer, \& the World Bank. (2002). Understanding and measuring social capital, a multidisciplinary tool for practitioners. Washington, D.C., World Bank. http,//dx.doi.org/10.1596/0-8213-5068-4

Halpern, David. (2001). Moral values, social trust and inequality, can values explain crime? British Journal of Criminology.

Hean, Sarah, Cowley, Sarah, \& Forbes. Angus. (2003). The M-C-M cycle and social capital. Social Science Medicine, 56, 1061-72.

Hogan, David, \& Owen, David. (2000). Social capital, active citizenship and political equality in Australia. Pp. 74 - 104 in Social capital and public policy in Australia, edited by Ian Winter. Melbourne, National Library of Australia.

Jack, Gordon, \& Jordan, Bill. (1999). Social capital and Chile welfare. Children and Society, 13, 242-256. http,//dx.doi.org/10.1002/CHI565

Kilpatrick, Sue. (2000). How social capital facilitates learning outcomes for small family businesses. University of Tasmania.

Labonte, Ronald. (1999). Social capital and community development. Australian and New Zealand Journal of Public Health, 23, 430-433. http,//dx.doi.org/10.1111/j.1467-842X.1999.tb01289.x

Lazega, Emmanuel, \& Pattison, Phillipa. E. (2001). Social capital as social mechanisms and collective assets, The example of status auctions among colleagues. in Social capital theory and research, edited by Ronald Burt. New York, Aldine de Gruyter. 
Lin, Nan. (2001a). Building a Network Theory of Social Capital. Pp. 3-30 in Social capital, theory and research, edited by Ronald Burt. New York, Aldine de Gruyter. http,//dx.doi.org/10.1017/CBO9780511815447.002

Montgomery, John. D. (2000). Social capital as a policy resource. Policy Sciences, 33, 227-243. http,//dx.doi.org/10.1023/A,1004824302031

Nahapiet, J., \& Ghoshal, S. (1998). Social Capital, Intellectual Capital, and the Organizational Advantage. The Academy of Management Review, 23(2), 242-266.

Newton, Kenneth. (2001). Trust, social capital, civil society, and democracy. International Political Science Review, 22, 201-214. http,//dx.doi.org/10.1177/0192512101222004

Putnam, Robert. D. (1995). Bowling alone, Americas declining social capital. Journal of Democracy, 6, 65-78. http,//dx.doi.org/10.1353/jod.1995.0002

Putnam. Robert. D, (1993). Making Democracy Work, Civic Traditions in Modern Italy, Princeton University press.

Putnam, Robert. D. (1999). Civic Disengagement in Contemporary America. Pp. 135-156 in Government and Opposition/Leonard Schapiro lecture. London School of Economics.

Robison, Lindon J., A. Schmid, Allan, \& Siles. Marcelo. E. (2002). Is social capital really capital? Review of Social Economy, 60, 1-24. http,//dx.doi.org/10.1080/00346760110127074

Sander, Thomas. H. (2002). Social capital and new urbanism, leading a civic horse to water. National Civic Review, 91, 213-221. http,//dx.doi.org/10.1002/ncr.91302

Snijders, T.A.B. (1999). Prologue to the measurement of social capital. The Tocqueville Review, 20, 27-44.

Szreter, Simon. (2000). Social capital, the economy, and education in historical perspective. In Social Capital, Critical Perspectives, edited by Tom Schuller. Oxford, Oxford University Press.

Uslaner, Eric. M. (2001). Volunteering and social capital, how trust and religion shape civic participation in the United States. Pp. 104 - 117 in Social Capital and Participation in Everyday Life, edited by Eric M. Uslaner. London, Routledge.

Weir, D. (2001) Management in the Arab World, A Fourth Paradigm?, paper submitted to EURAM conference, 2 Dec., 2001.

World Bank, (2011). Social Capital. [online] Available at, http,//data.worldbank.org/ [Accessed 12th April 2014]. 